\title{
NUEVAS APORTACIONES SOBRE LA CAPILLA RELICARIO DE VILLAGARCÍA DE CAMPOS (VALLADOLID)
}

\author{
YAYOI KAWAMURA ${ }^{1}$ \\ Universidad de Oviedo \\ Cristina Heredia Alonso ${ }^{2}$ \\ Universidad de Oviedo
}

\begin{abstract}
Partiendo de dos planos dibujados para la Colegiata de Villagarcía de Campos y otros documentos recientemente hallados, se indagan tanto el estado original de la capilla relicario construida por Magdalena de Ulloa (h. 1585) como su transformación en la capilla de Inés de Salazar (1660-1666). Asimismo, se analiza el proyecto de la capilla relicariofuneraria, no ejecutado, de Inés de Salazar (1613).

Palabras clave: capilla relicario; altar de reliquias; Villagarcía de Campos; Magdalena de Ulloa; Inés de Salazar; jesuitas.
\end{abstract}

\section{NEW CONTRIBUTIONS TO THE RELIQUARY CHAPEL OF VILLAGARCÍA DE CAMPOS} (VALLADOLID)

Based on two plants drawn for the Collegiate church of Villagarcía de Campos and other recently found documents, the original state of the reliquary chapel built by Magdalena de Ulloa (c. 1585) and its transformation into the chapel of Inés de Salazar (1660-1666) are studied. In addition, the authors analyzes the project for the reliquary-funerary chapel of Inés de Salazar (1613), which was not built.

Key words: reliquary chapel; altar of relics; Villagarcía de Campos; Magdalena de Ulloa; Inés de Salazar; Jesuits.

Como citar este artículo / Citation: Kawamura, Yayoi / Heredia Alonso, Cristina (2018): "Nuevas aportaciones sobre la capilla relicario de Villagarcía de Campos (Valladolid)". En: Archivo Español de Arte, vol. 91, núm. 361, Madrid, pp. 1-16. https://doi.org/10.3989/aearte.2018.01

\section{Capilla relicario: estado de la cuestión y nuevos documentos}

Sobre la historia de la Colegiata de San Luis de Villagarcía de Campos existe un corpus científico bien documentado y analizado por varios investigadores de prestigio ${ }^{3}$. En lo relativo a

\footnotetext{
1 kawamura@uniovi.es / ORCID iD: http://orcid.org/0000-0003-0901-2959. Es miembro del proyecto HAR 201564014-C3-1-R (CULTURBAN) del Ministerio de Economía y Competitividad, cofinanciado con fondos europeos del programa FEDER.

2 herediaalonso@gmail.com / ORCID iD: http://orcid.org/0000-0002-6711-4518.

3 Pirri, 1952: 13-24; 1970. Fernández Martín, 1952: 25-35. García Chico, 1953-54: 43-80. 1957: 65-85. Martín González, 1957b: 19-40. Rodríguez G. de Ceballos, 1966: 19-30. Bustamante García, 1982: 53-70. Pérez Picón, 1982.
} 
la capilla relicario del colegio, el estudio de la actual configuración de estilo barroco fue abordado por Martín González ${ }^{4}$ y Fernández Martín ${ }^{5}$ analizó aspectos relevantes sobre la capilla erigida en tiempos de Magdalena de Ulloa (1525-†1598) y su evolución.

En la actualidad son de público dominio los datos siguientes. La fundadora de la colegiata Magdalena de Ulloa, viuda de Luis de Quijada, mandó construir, antes de 1598, una capilla relicario adosada al último tramo de la iglesia, en el lado de la Epístola. Allí estaban depositadas diversas reliquias colocadas en gradas presididas por un cuadro del Salvador pintado por el jesuita Juan de la Peña. Años después, Inés de Salazar y Mendoza (¿?-†1636), esposa de Juan Quijada de Ocampo, manifestó, en su testamento de 1613, el deseo de construir una capilla relicario-funeraria en el lugar donde se estaba construyendo entonces la sacristía, es decir, detrás del testero de la iglesia. Este documento permite conocer el pretencioso aspecto de la misma, apuntando varios detalles que nos sugieren una emulación de lo que Ulloa había realizado: como los "lucillos" sepulcrales del matrimonio con estatuas en alabastro y la idea misma de la exposición de reliquias. El citado documento también señala que se adjuntó un plano de la capilla firmado por ella. Sin embargo, este proyecto fue una idea de Salazar en un momento dado de su vida. En su último testamento de 1636 - tras más de diez años de residir como viuda en el convento de San Quirce de Valladolid - cambió su voluntad al nombrar como testamentarios a tres padres jesuitas del colegio, dejándoles total libertad para escoger la ubicación definitiva de la capilla relicario-funeraria, pero no solo para el matrimonio sino también para los padres jesuitas del colegio. Se borraba entonces cualquier rasgo de presuntuosidad, puesto que retiró la grandeza de sus sepulcros para que su enterramiento fuese dispuesto sobriamente en el enlosado. Así, en 1656, los padres jesuitas determinaron que la capilla relicario-panteón fundada por Salazar fuese ubicada en el mismo lugar de la capilla relicario primitiva fundada por Ulloa. Se iniciaba entonces la transformación de este espacio en una capilla barroca, que es la que hoy conocemos.

Nuestras aportaciones para la historia de la capilla relicario se sustentan en dos dibujos hallados en el Archivo Histórico Nacional y otros documentos. Ambos dibujos son localizados junto a una serie de dotaciones, que son juros de diversas propiedades de Inés de Salazar' ${ }^{6}$ El primero muestra la configuración concreta de la nueva capilla relicario-funeraria proyectada por Inés de Salazar en 1613. Es, precisamente, aquella "planta firmada de mi nombre de como ha de ser dicha capilla" según el testamento de 1613. El segundo se corresponde con un proyecto de enlosado y reja para la capilla relicario firmado por Gómez del Rebollar ${ }^{7}$, en el que se señalan el enterramiento de los padres jesuitas, la reja y la grada.

Por otro lado, en el archivo del Colegio Noviciado San Luis de Villagarcía de Campos localizamos un documento que señala la disposición de las reliquias sobre las gradas en la época de Ulloa, así como otros apuntes de los padres visitadores que revelan más aspectos de la capilla y su transformación. Partiendo de estos nuevos datos, los de las crónicas de los jesuitas del siglo XVII — especialmente de Diego de Sosa, Luis de la Puente y Luis de Valdivia ${ }^{8}$ - y las investigaciones anteriores, hemos realizado nuevas consideraciones sobre la capilla relicario original de Ulloa, el proyecto de la capilla relicario-funeraria de Salazar y la transformación de la capilla relicario de Ulloa en la capilla barroca que actualmente conocemos.

\footnotetext{
${ }^{4}$ Martín González, 1952: 43-52.

5 Fernández Martín, 1998: 179-192.

${ }^{6}$ Capellanía del Relicario de la $S .{ }^{a} D .{ }^{a}$ Inés. Aquí están dos copias auténticas del juro de 70 ducados que sobre las alcavalas de la ciudad de Úbeda gozava D. ${ }^{a}$ Inés de Salazar y de que en falta de subzesión en los llamados hizo donación a la capilla del Relicario y de su fábrica, s./fecha. Archivo Histórico Nacional, Madrid (AHN), Juros, 2060.1.

7 Plano dibujado por Gómez del Rebollar, s/fecha, AHN, Mapas, planos y dibujos (MPD), Consejos, 1743.

8 Puente, 1615. Sosa, Diego de, ms., s/fecha: Espiritualísima vida y excelentes virtudes del Santo y Venerable Padre Luis de la Puente de la Compañía de Jesús. Copia mecanografiada del original, cap. 7. En el Archivo del Colegio Noviciado de San Luis de Villagarcía de Campos, Villagarcía de Campos (ACSLVC), caja 17. 5-10. Valdivia, Luis de, ms., s./fecha: Historia de los Colegios de la Compañía de Jesús en la provincia de Castilla. Copia mecanografiada del original, sección 4, f. 136v. En la Biblioteca Instituti Historici Societatis Iesu, Roma (BIHSI), 6 F 21. Nuestro agradecimiento a José Blanco Perales.
} 
Fig. 1. Planta baja de la colegiata de San Luis de Villagarcía de Campos: iglesia, sacristía, capilla relicario y parte del colegio. Detalle del plano elaborado por Manuel López, h. 1960 , ACSLVC, caja 2, $10-4$, carpeta B.

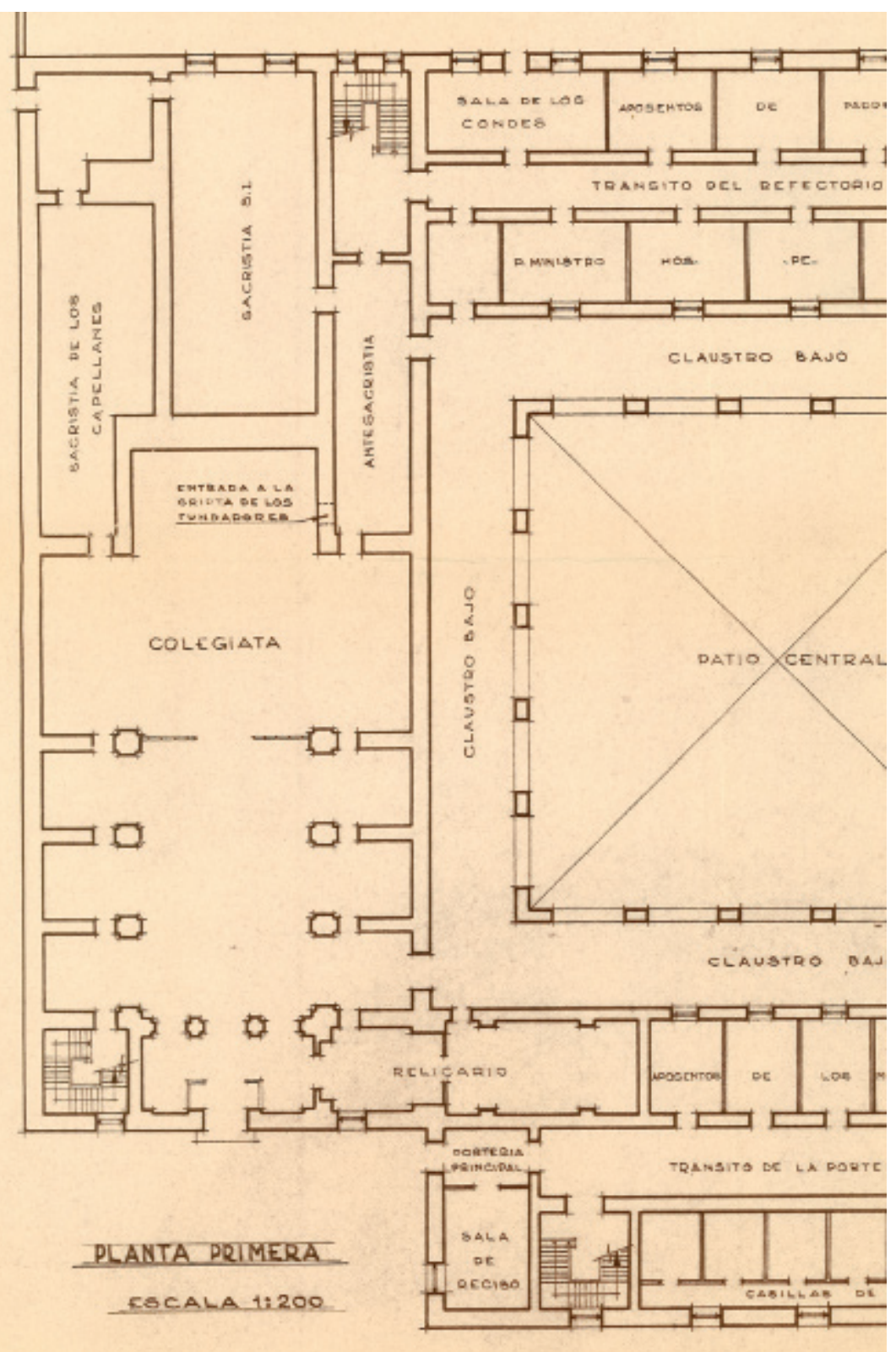

\section{Magdalena de Ulloa y el primer relicario}

Las primeras crónicas sobre el colegio nos trasmiten que la idea de erigir una capilla relicario fue fruto de la estrecha relación mantenida entre Magdalena de Ulloa con la propia Compañía de Jesús. El relicario formaba parte de la panda norte del claustro del colegio (fig. 1), cuyo edificio "al presente está hecho" en 1576 según Ulloa, quien entonces ordena terminar todo el colegio según la traza de Valeriani9 ${ }^{9}$. De la correspondencia mantenida entre los padres de Villagarcía con

${ }^{9}$ Escritura de la donación de Magdalena de Ulloa, 18 de diciembre de 1576, ACSLVC, caja 2, 6-8, carpeta J, ff. 3 r. y 4 r. 
el General de la Compañía Claudio Aquaviva $(1543-\uparrow 1615)$ se desprende que en 1585 ya estaba construido y amueblado el relicario, al indicar tan sólo restaba trasladar a ella el Santísimo Sacramento $^{10}$.

A lo largo de su vida, Ulloa sintió una especial adoración al Santísimo Sacramento y devoción a los santos expresada en la veneración de sus reliquias ${ }^{11}$, lo cual constituía uno de los pilares de la doctrina tridentina. Su posición en la corte del emperador Carlos V como aya de Juan de Austria, además de su estrecha relación con la Compañía de Jesús, le sirvieron para atesorar un sustancioso número de sagradas reliquias ${ }^{12}$. Por tanto, es muy probable que la idea de proyectar una capilla relicario como uno de los espacios de importancia dentro del noviciado ya se habría contemplado desde los primeros momentos.

La estrecha relación que Ulloa mantuvo con el jesuita Baltasar Álvarez $(1533-\dagger 1580)^{13}$ como su director espiritual desde 1570 hubo de ser determinante para el proyecto de la capilla relicario. Desde el momento en que Álvarez se convirtió en el rector del colegio (1576-1580), el jesuita debió trasmitir a la fundadora las necesidades espirituales de sus novicios. En consecuencia se habría planteado la creación de un espacio de oración y contemplación, que no solo actuaría como depósito de las sagradas reliquias sino también como el lugar en el que los novicios realizasen los ejercicios espirituales ignacianos ${ }^{14}$ ante ellas.

Las crónicas redactadas por algunos jesuitas nos revelan cómo era en su origen esta capilla y cómo se disponían las reliquias. Diego de Sosa $(1556-\dagger 1639)$, que fue rector el colegio ${ }^{15}$, señala: "una capilla muy devota (...), donde está el Santísimo Sacramento y grande número de reliquias de Santos, que le rodean, ricamente guarnecidas en un tabernáculo muy curioso y adornado, que todo hace un santuario de gran devoción"16.

Luis de la Puente $(1554-\dagger 1624)$ indica que, durante el gobierno de Álvarez, se construyó "una capilla aparte, donde colocó muchas e insignes reliquias que tenía muy bien adornadas, trazando el Padre Baltasar Álvarez que estuviese allí el Santísimo Sacramento, para que los novicios con mayor devoción recogiesen aquel sagrario y santuario a tener su oración y exámenes; y encima de las reliquias que estaban repartidas por sus gradas puso una hermosa imagen del que se llama Juan de la Peña (...) y en el frontispicio de la capilla dijo se pusiese este letrero: Ego sum vitis, vos palmites $(\ldots)$ "..17.

Complementando este relato, en 1618 Luis de Valdivia (1561-†1642) apostilló que se trataba de la "primera capilla de la iglesia, al entrar por la puerta a mano derecha, a la cual se juntó con un pedazo del cuarto y se hizo una iglesia con su sacristía, y tribuna en lo alto de la sacristía, y con una hermosa reja que toma el alto de ella y muchas gradas donde se colocaron las reliquias,

10 Carta del Padre Diego de Morales al Padre Claudio Aquaviva, Medina del Campo, 23 de julio de 1585, ACSLVC, caja 17. 5-10. Copia mecanografiada del original conservado en el Archivum Romanum Societatis Iesu, Roma (ARSI), Hisp. 130, ff. 237r.-238r.

11 Villañafe, 1723: 440-442.

12 En la década de 1580 se observan un gran número de pagos realizados por Magdalena de Ulloa a distintos artesanos vallisoletanos por la confección de diversas custodias y cajitas para alojar las reliquias. Carta de pago a Juan de Calderón, platero, de ocho cajas de plata,12 de abril de 1581; Carta de pago a Cosme de Azcuitia, pintor, de la pintura de las cajas, 29 de enero de 1582; Carta de pago a Andrés Errada, de 200 custodias, 14 de noviembre de 1583; Carta de pago a Gabriel de Barreda, pintor, de la pintura de catorce cajas, 27 de junio de 1582; Carta de pago a Diego de Roa, entallador, de las custodias que hace para Doña Madalena, s/fecha, AHN, Clero, jesuitas, legajo 912, carpetas 1 y 2: Recibos y justificantes de pago de D. ${ }^{a}$ Magdalena de Ulloa, del Colegio y de particulares, 1556-1599, s/f.

13 O’Neill / Domínguez, 2001: 91-93.

14 Idiáquez, 1818: 10-13.

15 Diccionario de jesuitas relacionados con Villagarcía. 1576-1767, ACSLVC, caja 6, carpeta 0. Figura como rector en 1600

${ }^{16}$ Sosa, Diego de, ms., s/fecha: Espiritualísima vida y excelentes virtudes del Santo y Venerable Padre Luis de la Puente de la Compañía de Jesús. Copia mecanografiada del original, cap. 7. ACSLVC, caja 17. 5-10.

17 Puente, 1615: 159-160. "EGO SUM VITIS VOS PALMITES. QUI MANET IN ME, ET EGO IN EO, HIC FERT, FRUCTUM, JOAN". Se trata de una cita del capítulo XV del Evangelio de San Juan: "Yo soy la vid, vosotros los sarmientos. El que está en mí y yo en él lleva muchos frutos, porque sin mí no podéis hacer nada". 
Fig. 2. Plantas baja y superior de la capilla relicario, con la zona de la primitiva capilla relicario señalada con un tono diferenciado.

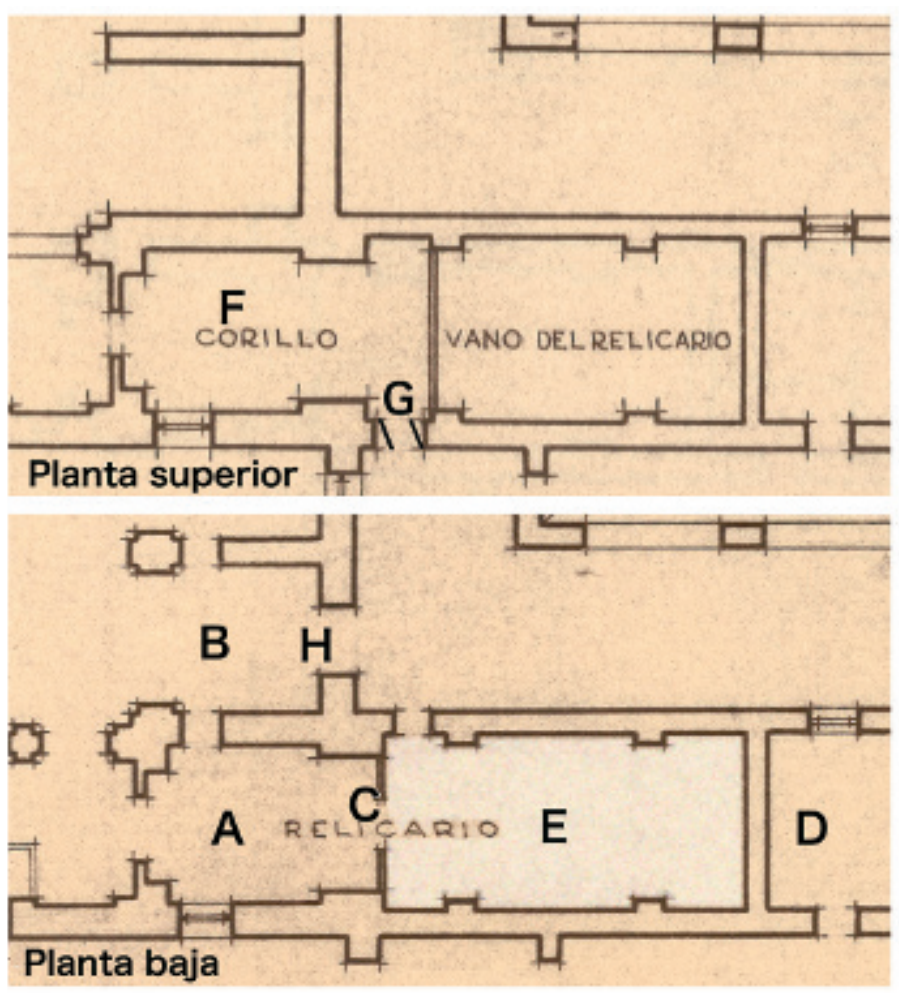

por ser muchas, en doce custodias y varios castillos de vidrio muy bien aderezados y en varios relicarios y cajas de cristal" 18 .

Todos estos datos ya han sido abordados por distintos autores ${ }^{19}$, quedando bien claro el lugar donde se ubicó el primer relicario y la función expresa del mismo. No obstante, lo que no ha sido objeto de análisis ha sido la organización de este espacio, su extensión y su función dentro del colegio.

En cuanto a su extensión inicial, consideramos que la capilla era más reducida que la actual. Al observar el plano del conjunto (fig. 2), queda claro que la actual invade el espacio del templo ya que la portada con el escudo de Inés de Salazar se localiza dentro de la zona que corresponde al pie del templo (fig. 2A). Si tenemos en cuenta que inicialmente la primera capilla colateral del lado de la Epístola (fig. 2B) estaba dedicada al espacio de confesión para las mujeres "pecaminosas" 20 , por las que Magdalena de Ulloa tenía especial preocupación y cuidado, entendemos que la primera crujía de la actual capilla servía para el paso de esas mujeres hacia los confesionarios. Un documento de 1585, del archivo de Villagarcía, corrobora esta hipótesis ya que indica que en la entrada de la capilla relicario desde el templo había una puerta de madera, normalmente cerrada, y detrás una reja ${ }^{21}$ (fig. 2C).

18 Valdivia, Luis de, Historia de la Colegiata de la Provincia de Castilla, ms., s./fecha: BIHSI, 6 F 21. Copia mecanografiada del original, sección 4, f. 136v.

19 Pirri / otros, 1952. Pérez Picón, 1982. Rodríguez Herreras (coord.), 1998.

20 "Se acomodarán los confesionarios a la puerta de la capilla de las reliquias". Visita del P. Antonio Marcén, 1585; Visita del P. Francisco Juárez, Viceprovincial, 30 de septiembre de 1662, en ACSLVC, archivador VI, carpeta C: Libro General de Ordenaciones y Memoriales de los Padres Provinciales en sus visitas a Villagarcía, desde su comienzo hasta su expulsión (1574-1767).

${ }_{21}$ Carta del Padre Diego de Morales al Padre Claudio Aquaviva, Medina del Campo, 23 de julio de 1585, ACSLVC, caja 17. 5-10. Copia mecanografiada del original, ARSI, Hisp. 130, ff. 237r.-238r. 
Por lo tanto, originalmente la capilla era un espacio de nave única con solo tres tramos, donde se combinó la bóveda de cañón sobre fajones - el primero y el tercer tramos - con la media naranja ciega en el segundo. El tramo central era y es casi cuadrado, siendo los dos restantes más reducidos de superficie.

Los primeros jesuitas declararon que el lugar era "estrecho y falto de luz"22, por lo que apenas tendría vanos. Desde el exterior, en la pared meridional de la capilla, tan sólo se reconoce un vano original, aún abierto, además de apreciarse otros dos abiertos en época posterior y otros tres vanos y una puerta, posteriormente abiertos y actualmente tapiados, huellas de haber sufrido varias fases de transformación.

Nada se sabe de la autoría del proyecto arquitectónico del primer relicario. Pirri apuntó el nombre del lego jesuita Pedro Amado (Mato o de Matos) ${ }^{23}$, opinión desbancada por posteriores investigadores ${ }^{24}$. Su intervención en la capilla tuvo lugar en $1660^{25}$, por tanto, no pudo haber intervenido, antes de 1598.

Si partimos de la idea de que este espacio fue construido como parte integrante del colegio, cabe la posibilidad de que hubiese sido Juan de Nates el responsable de su ejecución material. Los trabajos de Nates en la fábrica de la iglesia y del colegio se registran desde $1572^{26}$. Ahora sabemos que su participación se prolongó por lo menos hasta $1579^{27}$, fecha en que debían de estar finalizándose las obras de la iglesia. El traspaso de obras efectuado por Nates a Juan de Negrete en $1572^{28}$ debió de ser algo circunstancial a la vista de los nuevos documentos localizados. En distintos pagos registrados en torno a 1578-1579, Nates encabeza una cuadrilla de constructores. Los cambios sustanciales introducidos por Pedro de Tolosa sobre la traza de Hontañón para la iglesia supusieron la introducción del clasicismo en Villagarcía y, por tanto, entendemos que el nuevo estilo se habría propagado a la capilla relicario, siendo Nates el responsable de su ejecución.

La capilla se concibió como una iglesia de pequeñas dimensiones, con su propia sacristía y tribuna o corillo para los novicios sobre ella, facilitándoles la contemplación del Santísimo y las reliquias. Es decir, tanto la sacristía como la tribuna se emplazaban en el lugar opuesto al templo y una encima de la otra (fig. 2D), con acceso desde el colegio, lo que proporcionaba la guarda de los ornamentos litúrgicos y el recogimiento de los novicios en sus ejercicios espirituales.

En cuanto a la ubicación de las reliquias en gradas, Fernández interpreta que se disponían adosadas al testero de la capilla, lugar posteriormente ocupado por el retablo actual ${ }^{29}$. Hipótesis poco probable puesto que precisamente en ese muro se emplazaron la sacristía y, sobre ella, la tribuna $^{30}$. En caso de que las gradas se dispusieran en esa pared, los novicios no podrían contemplarlas, lo que habría dificultado sus prácticas espirituales. Por lo tanto, creemos que el graderío estaba situado en el tramo central justo debajo de la cúpula (fig. 2E). De esta manera, la capilla ofrecía visibilidad desde ambos lados: del templo y del colegio, mostrando un carácter centralizado. La descripción de Sosa de que las reliquias "rodean" al Santísimo y está "guarnecidas en un tabernáculo" podría describir esta configuración. Más tarde, en 1666, cuando se desmontó el

22 Pérez Picón, 1982: 142.

23 Pirri, 1952: 13-24.

24 Si bien Martín González siguió el criterio de Pirri, en posteriores estudios rechazó esta hipótesis. Martín González, 1951-1952: 43-52; 1957a: 85-86. Rodríguez de Ceballos, 1969: 91. Fernández Martín, 1998: 179-192. Pérez de Castro, 2000: 269-290.

${ }^{25}$ El lego jesuita Pedro de Matos entró a formar parte de la Compañía en 1623, trabajando ampliamente en la provincia de Castilla. En el caso de Villagarcía, en 1660, se le abonan una serie de pagos por participar en "la asistencia de la obra del relicario" y sus desplazamientos desde Salamanca, donde se encontraba participando en las obras de la Real Clerecía de San Marcos. Fernández Martín, 1998: 179-192.

26 García Chico, 1940: 64-65; 1979: 165.

27 Libro de destajos, 1578-1579, AHN, Clero, jesuitas, legajo 912, carpeta 1: Recibos (1556-1599), recibos y justificantes de pago de Doña Magdalena de Ulloa, del Colegio y sus particulares, s./f.

28 García Chico, 1940: 64-65.

29 Fernández Martín, 1998: 179-192.

30 Pérez Picón, 1982: 159-162. 
altar de reliquias, el documento ${ }^{31}$ habla de "quitar el tabernáculo", lo cual nos sugiere una estructura de planta centralizada.

Por lo tanto, creemos que desde el momento inicial las reliquias se emplazaban en el tramo central, repartidas por un graderío de forma piramidal escalonado. Esta estructura se encontraba presidida por una imagen del Salvador. En cuanto a la disposición del cuadro, aunque La Puente señalaba que se encontraba "encima de las reliquias"32, es difícil pensar que la imagen se hubiese colgado de la bóveda, suspendida sobre ellas. Más bien pensamos que se encontraba ubicada encima de la puerta de acceso desde el templo, bien visible por los novicios "encima de las reliquias".

De las crónicas de la época se comprende que el conjunto permanecía velado la mayor parte del tiempo por medio de grandes cortinajes. Estos velos, únicamente eran descorridos en fechas muy señaladas, lo que suscitaba la emotividad y devoción de los novicios, además de contribuir a una cierta teatralidad, un preludio de la escenografía propia del Barroco ${ }^{33}$.

Un interesante documento hallado en el archivo de Villagarcía titulado "Memoria de las Reliquias, Imágenes y cosas devotas que ay en este Sagrario"34, revela la distribución primitiva de las reliquias en el graderío. El documento, fechable en torno a 1585, enumera siete gradas que componían el altar de reliquias, número probablemente determinado por razones místico-teológicas $^{35}$. En las siete gradas se hallaban, por lo menos, 674 reliquias identificadas.

Los relicarios eran de gran variedad en formas y materiales: pequeños dípticos, retablos de diverso tamaño y ornamentación, arquillas, cofres, cajas, vasos, pirámides o figuras humanas de medio cuerpo o extremidades con tecas; hechos de cristal, vidrio, plata, bronce, madera policromada, alabastro, concha de tortuga, cuerno de unicornio o ébano; aparte de otros objetos como cruces, figuras de ángeles, tarjetas bordadas, etc. Un conjunto, que manifiesta el gusto preciosista manierista del momento, un wunderkammern religioso, propio de la mentalidad contrarreformista $^{36}$.

En el texto no se hace alusión a la presencia del Santísimo debido a que se relacionan solo las reliquias. No obstante, en 1585 constatamos su inmediato traslado a la capilla, por lo que se entiende que en lo alto de este conjunto se situaba el Santísimo.

El uso de gradas no suponía una novedad, ya que se detectan otros ejemplos de este modelo anteriores al de Villagarcía en distintas órdenes religiosas del ámbito peninsular, a lo largo del siglo XVI, para los altares tanto efímeros como permanentes. En el monasterio de San Pablo de Valladolid, la orden dominica utilizó un graderío similar para exponer las reliquias con motivo de la celebración del bautismo de Felipe II (1527) ${ }^{37}$. Asimismo, los cartujos del monasterio de Aniago de Villanueva de Duero construyeron un graderío escalonado apoyado en el muro del testero de su capilla relicario $(1542-1546)^{38}$. De forma idéntica se obró con motivo de la traslación de las reliquias de los Santos Justo y Pastor a Alcalá de Henares (1568) ${ }^{39}$ y también en el recibimiento de otros restos en la iglesia de San Roque de Lisboa $(1588)^{40}$. No obstante, el ejem-

31 "Varios peones que metieron piedra en el sagrario y ayudaron a quitar el tabernáculo". Obras del relicario, 1666, AHN, Clero, jesuitas, libro 492: Libro de Cuentas de la Capilla del Relicario, fundada por D. ${ }^{a}$ Inés de Salazar y Mendoza, en el Colegio de la Compañía de Jesús de Villagarcía. Años 1637-1756, f. 80r.

32 Puente, 1615: cap. XXXV, 159. La obra fue pintada por el novicio Juan de la Peña. La tabla fue reubicada en el interior de la colegiata en varias ocasiones. Desde 1578, estuvo en el relicario y con la reforma barroca se trasladó al anteprofundis, hasta 1678, momento en que se dispuso en el retablo de la capilla colateral del Salvador. Mide aproximadamente $220 \times 137$. Reliquias de Villagarcía, 8 de abril de 1678, ACSLVC, caja 17, 5-10, carpeta B, s/f.

33 “(...) particularmente los días que se tiran los velos y quedan las reliquias descubiertas, lo qual no se haze ni se muestran sin expressa licencia del Superior (...)”. Valdivia, Luis de, Historia de la Colegiata de la Provincia de Castilla, ms., s./fecha: BIHSI, 6 F 21. Copia mecanografiada del original, sección 4, f. 136v.

${ }^{34}$ Memoria de las reliquias, s/fecha, ACSLVC, Reliquias de Villagarcía, caja 17, 5-10, carpeta B.

35 Chevalier/ Gheerbrant, 2007: 943-945.

36 Morán / Checa, 1985: 173-178.

37 Sandoval, 1604: 827.

38 Morales, 1568: 87 y 134. Urrea (coord.), 2009: 12-15.

39 Morales, 1765: 196-198.

${ }^{40}$ Campos, 1588: 12. 
plo más claro es el del relicario de las Descalzas Reales de Madrid (1559-1564) ${ }^{41}$, en el que aún se conserva la estructura escalonada sobre la que se asientan las reliquias. La singularidad del caso de Villagarcía fue su disposición con doble frente en el centro de la capilla, si bien es cierto que los jesuitas de Valencia usaron un modelo centralizado en la conmemoración de la conquista de Valencia en $1639^{42}$.

\section{La capilla relicario-funeraria proyectada por Inés de Salazar y Mendoza en 1613}

Ante la falta de descendientes en el matrimonio de los Quijada-Ulloa, el señorío de Villagarcía pasó a manos de otros parientes recayendo en manos de Juan de Quijada de Ocampo casado con Inés de Salazar y Mendoza. Esta dama de alcurnia, hija del Consejero y Secretario de Cámara del rey Felipe II, Juan Vázquez Salazar, también sintió una especial predilección por la Compañía de Jesús ${ }^{43}$.

Inés de Salazar hizo redactar su testamento hasta en cuatro ocasiones, cuyo contenido varió en función de sus circunstancias personales ${ }^{44}$. Concretamente, el segundo de 1613 y el cuarto de 1636 dejaron claras disposiciones acerca del enterramiento de su marido y el suyo propio, subrayando su intención de descansar juntos en la iglesia de Villagarcía de Campos. Estos textos describen sus deseos respecto a los enterramientos en dos momentos diferentes de su vida ${ }^{45}$.

En el testamento de 1613 dispuso la creación de una capilla relicario-funeraria en el lugar donde se estaba construyendo la sacristía, justo detrás de la cabecera de la iglesia "a espaldas del altar mayor" ${ }^{46}$. Precisamente es en este texto donde se indica que se adjunta "una planta firmada de mi nombre de como ha de ser dicha capilla" 47 , la cual corresponde a uno de los documentos localizados en el Archivo Histórico Nacional ${ }^{48}$. Se trata de un dibujo realizado con tinta negra sobre papel verjurado conservado con visible deterioro en la zona central (fig. 3).

En la parte superior del mismo, aparece una sencilla filacteria enmarcando el título que reza: "Ortographía y Sección de interior de la Capilla del Sagrario que / mira al Mediodía". En la parte inferior, un sello lacrado y la rúbrica de la testadora "Doña Ynes de / Salazar y Mendoça". En la parte derecha se halla la marca de agua: una filigrana de forma romboidal rellena de pequeños lóbulos, de la que pende una media luna menguante.

A excepción del pitipié localizado en la parte inferior del dibujo, no se aprecian más acotaciones numéricas, aunque sí textuales que permiten aclarar ciertos aspectos de la traza. Es llamativo el uso de distintas tonalidades de tinta y el sombreado con el fin de crear efectos en la profundidad. El dibujo, por lo tanto, es más pictórico e ilusionista que estrictamente ortogonal, probablemente debido a su carácter de ser aún una propuesta.

El dibujo ofrece la imagen de una estancia dividida claramente en tres partes: zona de entrada con una tribuna y sacristía, una nave alargada y la capilla-relicario del Santísimo. Atendiendo al pitipié, la estancia tendría una longitud total de 110 pies $(30,6 \mathrm{~m})$ incluyendo la capilla del Santísimo en la cabecera de 24 pies $(6,7 \mathrm{~m})$, con una altura de la nave de 40,7 pies $(11,3 \mathrm{~m})$. La

${ }^{41}$ Carrillo, 1616: ff 48r. y 51v.-52r.

42 Orti, 1640: 98-99.

43 Pérez Picón, 1982: 140-144.

44 Ella misma lo confirma en su último testamento de 1636. Testamento de Inés de Salazar y Mendoza, del 28-I1636, ante Luis de Palencia. Archivo Histórico Provincial de Valladolid (AHPV), protocolos notariales de Valladolid, legajo 1591, ff. 2026r. 2035v.

45 García Chico, 1953-1954: 43-80. Fernández Martín, 1998: 179-192.

46 "En el sitio donde está comenzada a fabricar la sacristía para los religiosos de dicho colegio es la espalda del altar mayor". Testamento de Inés de Salazar y Mendoza, del 13-III-1613, ante Blas López Calderón. García Chico, 1953-1954: 43-80.

47 Testamento de Inés de Salazar y Mendoza, de 1613. García Chico, 1953-1954: 43-80.

48 Ortographia y sección interior de la Capilla del Sagrario que mira al mediodía, 1613, AHN, MPD, consejos, 1742. 


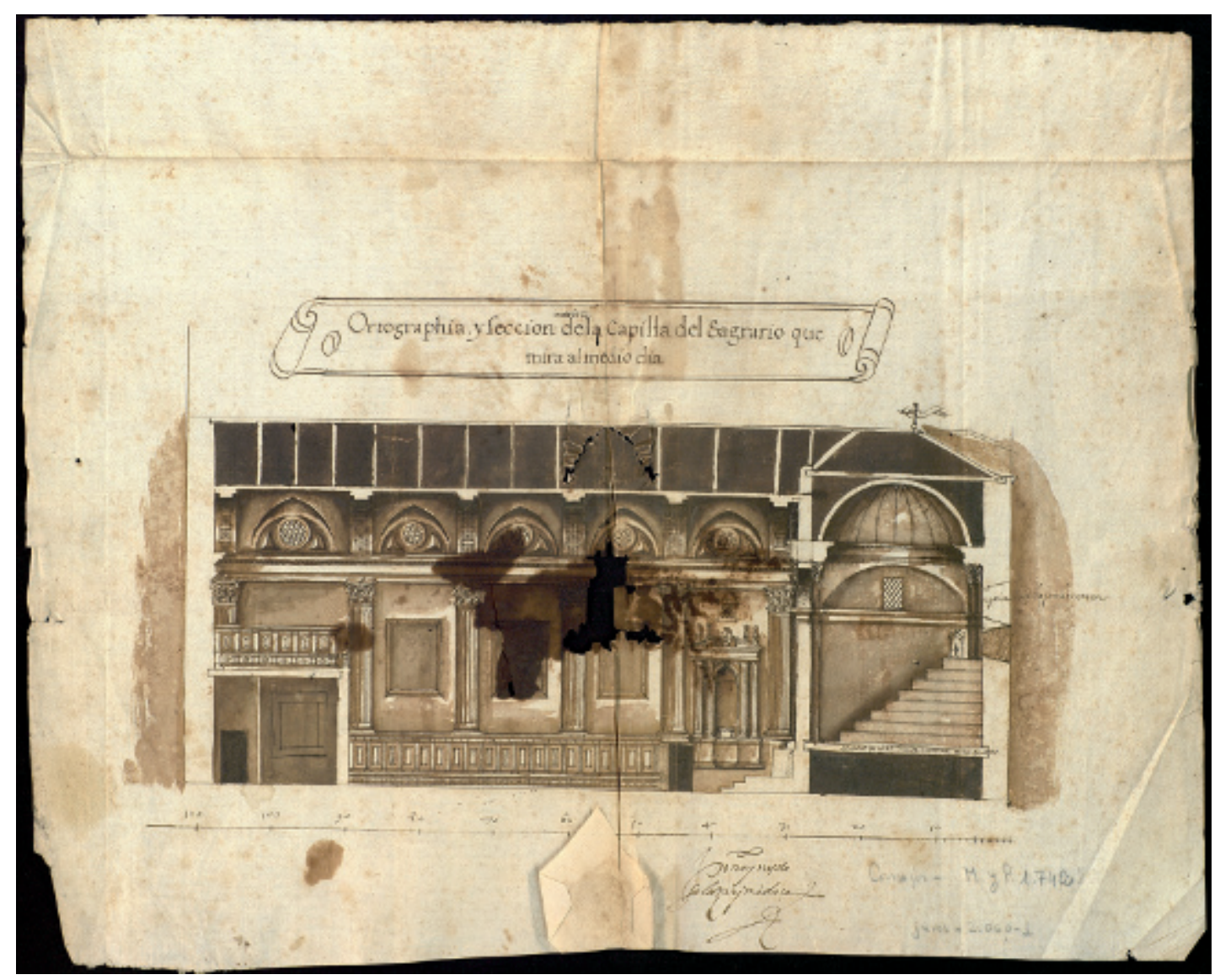

Fig. 3. Plano de la capilla relicario-funeraria que planteó Inés de Salazar en 1613. AHN, Mapas, planos y dibujos, Consejos, 1742.

cúpula de media naranja situada en la cabecera mide 43,3 pies (12 m) de altura. En la capilla del Santísimo se hallan gradas cuya altura total es de 20 pies $(5,6 \mathrm{~m})$. A través de estas dimensiones, podemos hacernos una idea de la magnitud del espacio en el que deseaba disponer su enterramiento.

La zona de entrada, según la testadora, debía de ser "lo más desaogada posible para pasar olgadamente la procesión del Corpus Christi y demás procesiones"49. La tribuna situada al pie estaría destinada a la asistencia de los novicios al culto. La balconada está decorada con placas animadas con motivos geométricos.

En cuanto a la nave, recoge el influjo clasicista siguiendo el estilo del templo principal. Se divide en cuatro tramos, con un plinto corrido de cierta altura, sobre el que se apoyan pilastras estriadas corintias. El plinto está decorado con motivos geométricos poliédricos. Sobre las pilastras recorre un entablamento, en el que descansan los arcos fajones de la bóveda de cañón con lunetos, cuyos intradoses están ornamentados con florones, al igual que en la iglesia. En cada luneto se encuentra un vano termal constituido por un óculo flanqueado por puntas de diamantes triédricas, en las que se denota la estela de Juan de Nates. Los entrepaños están destinados a "quadros de ymaginería al óleo" 50.

49 Testamento de Inés de Salazar y Mendoza de 1613. García Chico, 1953-1954: 43-80.

50 Testamento de Inés de Salazar y Mendoza de 1613. García Chico, 1953-1954: 43-80. 
El cuarto tramo rompe con el plinto corrido, donde se proyecta un cenotafio. Está constituido por un alto basamento, pilastras estriadas pareadas de orden toscano que flanquean un arco de triunfo peraltado con armas en la clave, entablamento y frontón triangular partido en la cúspide con el escudo de la Compañía. Pirámides rematadas con bolas de filiación escurialense coronan el conjunto. El interior de este "lucillo" acogería dos bultos de alabastro, el de la fundadora y el de su marido sobre reclinatorio, ambos orientados hacia el altar, como una clara emulación de lo proyectado por Magdalena de Ulloa. En el basamento se grabaría la leyenda sobre la promoción de la capilla ${ }^{51}$. Encima del "lucillo" se abre un pequeño vano con celosía.

En el mismo cuarto tramo, se encuentra el altar precedido por tres escalones. La fundadora deseaba que "delante del altar se dispusiera un retablo con quatro columnas" 52 , una de las cuales, de orden corintio, se aprecia en el dibujo.

Se observa un especial protagonismo en el último tramo, capilla relicario dedicada a la exaltación del Santísimo Sacramento, que permanecería oculta ya que detrás del altar - que entendemos que disponía de una amplia apertura en medio- iba a colocarse una "rexa dorada" sobre la que penderían los velos que impedirían ver las reliquias.

Dicha capilla está diseñada con un graderío profundo escalonado de trece niveles adosado al muro del testero ${ }^{53}$. El último estaría destinado a acoger el Santísimo. A esa altura el muro se abre para dar paso a un pequeño vano ${ }^{54}$, enmarcado por un par de columnas pareadas corintias. Se emplea así la luz dirigida de forma intencionada hacia el Santísimo, enfatizando una iluminación escenográfica muy propia de la arquitectura contrarreformista, recurso similar utilizado en El Escorial. Para dar algo más de luz, en la pared lateral justo por encima del entablamento se abre otro vano con celosía. Por último, una media naranja ciega, pero no vaída como en el templo, cubre el espacio.

Las consonancias existentes con respecto a la iglesia del colegio son más que evidentes, pero con mayor suntuosidad visual, como indicaba la testadora: una capilla "muy suntuosa, con su bóveda en blanco y oro, con pilastras doradas" 55 . Asimismo, llama la atención la espectacularidad que le otorgó al espacio de las reliquias. El retablo, con sendas imágenes de Nuestra Señora de la Concepción y de San Ignacio de Loyola a cada lado, iba a estar custodiado por dos ángeles mancebos a tamaño natural, que portarían en sus manos un hacha "para alumbrar al Santísimo Sacramento y las reliquias cuando se descubrieren" y un escudo "con la memoria escrita en él de las dichas reliquias por el orden que estuvieren en cada grada" 56 . Teniendo en cuenta el elevado número de ornamentos litúrgicos que debían de participar, además del propio ritual, a la hora de descorrer los velos, la visión del espacio supondría un fuerte impacto para los novicios y fieles asistentes en la celebración de las fiestas principales.

Por tanto, asistimos a una evolución con respecto al modelo empleado por Ulloa en el primer relicario, para dar paso a una escenografía plenamente barroca. Recordemos que Salazar deseaba que muchas de sus reliquias fuesen engastadas en "cuerpos y medios cuerpos". Su disposición en las gradas, culminadas con la presencia del Santísimo, además de los juegos de luz-sombra manejados intencionadamente, suscitarían el misticismo y la piedad propios de la ideología tridentina.

Finalmente, el proyecto fue desechado. En el testamento definitivo de 1636, Salazar dejó en manos de la Compañía la libre disposición acerca de su enterramiento ${ }^{57}$. Además, a través del

51 Testamento de Inés de Salazar y Mendoza de 1613. García Chico, 1953-1954: 43-80.

52 Testamento de Inés de Salazar y Mendoza de 1613. García Chico, 1953-1954: 43-80.

53 El mismo dibujo lo aclara: "en estas gradas han de entrar treze gradas". Ortographia y sección interior de la Capilla del Sagrario que mira al mediodía, 1613, AHN, MPD, consejos, 1742.

${ }^{54}$ En este caso, también se aclara: "aquí se ha de hazer la ventana".

55 Testamento de Inés de Salazar y Mendoza de 1613. García Chico, 1953-1954: 43-80.

56 Testamento de Inés de Salazar y Mendoza de 1613. García Chico, 1953-1954: 43-80.

57 "En el sitio que mis testamentarios escogiesen con la planta, forma y disposición que les pareciere mejor, más lucido y más conveniente”. Testamento de Inés de Salazar y Mendoza, del 28-I-1636, ante Luis de Palencia. Fernández Martín, 1998: 179-192. 
texto se denota un cambio en su actitud, mostrando una mayor humildad "como de una monxa con toda llaneça" 58 , "siendo más acorde con la auténtica función litúrgica de una capilla" 59.

\section{La reforma barroca de la capilla relicario}

Inés de Salazar dejó fundada una capellanía dotada con 140 ducados anuales por espacio de treinta años destinados a la nueva fábrica, nombrando al padre rector de Villagarcía como su patrono perpetuo ${ }^{60}$. Otros estudios ya han analizado lo acontecido posteriormente a los trámites legales, relativo tanto al emplazamiento de su enterramiento como a los pasos a seguir para la materialización de la capilla ${ }^{61}$. Aquí aportamos más datos para esclarecer cómo la Compañía resolvió este asunto.

Los problemas económicos impedían que las obras del colegio prosiguiesen con celeridad. La sacristía continuaba en estado de ejecución, al igual que otros cuartos del claustro, lo cual retrasó la decisión inmediata de construir la capilla de Salazar. En 1656 se llegó a la conclusión de que el mejor lugar para ubicarla sería el de la Capilla del Sagrario y Relicario erigida por Ulloa ${ }^{62}$. El jesuita Francisco de Zepeda alegaba que este lugar respondía perfectamente a las pretensiones de la promotora, ya que la antigua capilla era lo suficientemente hermosa y lucida, mientras que con el ahorro que supondría continuarían las obras del colegio: "el quarto comenzado del mediodía"63.

A partir de 1660, comenzó la remodelación del relicario para acomodarlo al nuevo gusto imperante ${ }^{64}$. Según las disposiciones testamentarias de Salazar, el espacio estaría bien delimitado, dejando dos tercias partes para el enterramiento de los jesuitas - hacia la puerta de entrada - y la otra para el de la dama y su esposo — en la parte delantera del altar- 65 .

Estructuralmente no sufrió modificaciones sustanciales, puesto que conservó su planta intacta, pero no así la direccionalidad de la capilla, obligando a realizar un cambio en la disposición de la tribuna y la sacristía. El coro fue desplazado a los pies de la capilla, el actual corillo (fig. 2F), destinando la pared del fondo al nuevo retablo-relicario. La tribuna primitiva fue cegada y en la planta superior se abrió desde el tránsito del noviciado un acceso diagonal, algo forzado, al nuevo coro (fig. 2G y fig. 4). La nueva sacristía se ubicó en el espacio que anteriormente estaba ocupado por los confesionarios de mujeres, con entrada directa desde el claustro y desde el relicario. En este espacio — que actualmente alberga la capilla colateral de San Josétodavía se conservan vestigios de la ornamentación de sus muros con pinturas al fresco detrás del retablo; ésta era la puerta de entrada a la sacristía desde el claustro: un gran arco de medio punto abocinado, policromado con cadenetas geométricas — cuadrados y círculos - en las jambas, y elementos florales y vegetales en el intradós (fig. $2 \mathrm{H} \mathrm{y} \mathrm{fig.} \mathrm{5).}$

En cuanto al espacio anteriormente ocupado por el graderío con las reliquias, se colocaron tres grandes losas para el enterramiento de la dama. Mientras, para dar sepultura a los jesuitas, el primer tramo de la capilla se prolongó, invadiendo el espacio que antiguamente cruzaban las penitentes de camino a los confesionarios.

\footnotetext{
58 Testamento de Inés de Salazar y Mendoza de 1636. Fernández Martín, 1998: 179-192.

59 Burrieza Sánchez, 2003: 7-61.

60 Testamento de Inés de Salazar y Mendoza de 1636. Fernández Martín, 1998: 179-192.

61 Pérez Picón, 1982: 140-148. Fernández Martín, 1998: 179-192.

62 Pérez Picón, 1982: 142.

63 Visita del Provincial Francisco de Zepeda, 15 de agosto de 1656, ACSLVC, archivador VI, carpeta C: Libro General de Ordenaciones y Memoriales de los Padres Provinciales en sus visitas a Villagarcía, desde su comienzo hasta su expulsión (1574-1767), f. 41r.

${ }^{64}$ Gastos del año 1660, 1660, AHN, Clero, jesuitas, libro 492: Libro de Cuentas de la Capilla del Relicario, fundada por D. ${ }^{a}$ Inés de Salazar y Mendoza, en el Colegio de la Compañía de Jesús de Villagarcía, ff. 70v.-72r.

65 Testamento de Inés de Salazar y Mendoza de 1636. Fernández Martín, 1998: 179-192.
} 


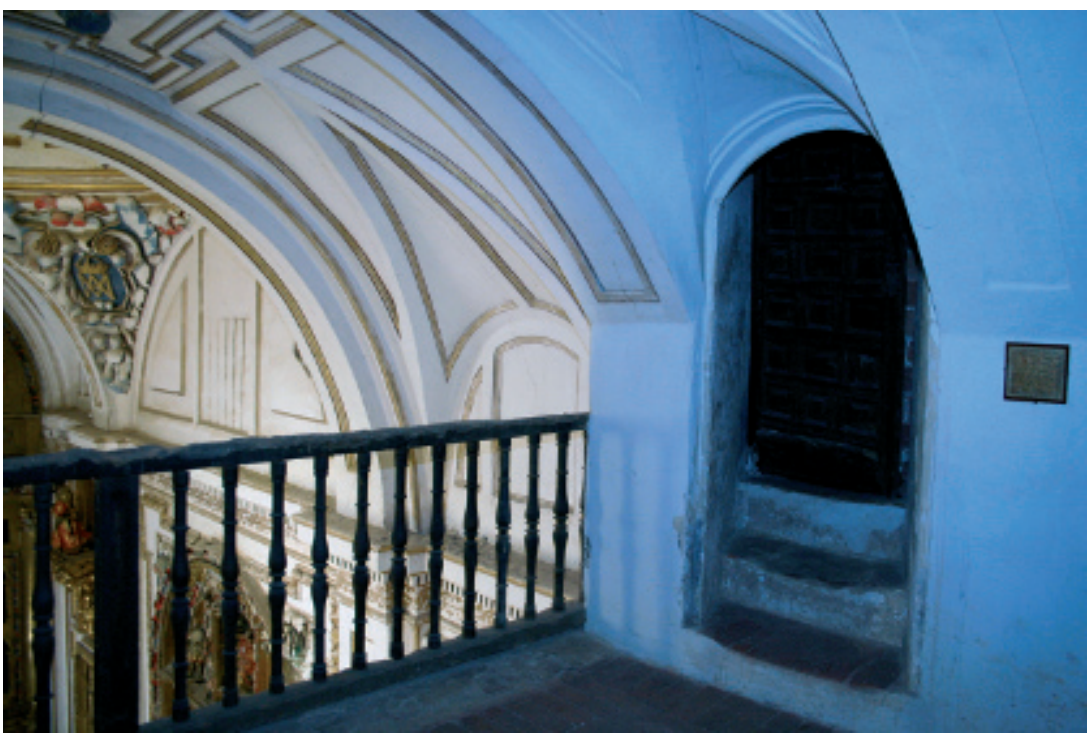

Fig. 4. Acceso al actual corillo desde la zona del noviciado.

El segundo dibujo del Archivo Histórico Nacional, ya citado, corresponde a un proyecto de enlosado y reja para la capilla relicario, firmado por "Gomez del Revollar me fezi" ${ }^{\circ}$, en el que se señalan el enterramiento de los padres jesuitas, la reja y la grada (fig. 6). Se trata de un dibujo realizado en papel verjurado sin filigrana, en muy buen estado de conservación. Presenta pitipié en la parte inferior derecha y otras acotaciones. A la derecha, el tracista precisó con una cuadrícula en diagonal junto a una moldura la "demostrazión del enlosado de junto a la grada y canpo que ai entre el pedrestal y rega [sic] a la parte señalada A". Esa parte señalada como "A" efectivamente se dispone delante de la grada del altar en el que se iba a situar el "asiento de la custodia". El dibujo coincide con las disposiciones testamentarias de Salazar: el espacio de enterramiento de los jesuitas a los pies de la nave, la reja intermedia, que da paso al enlosado — su enterramiento - y el altar, aunque las tres losas aún no están señaladas.

La situación actual (fig. 7) no es muy diferente del planteamiento de Rebollar. El enlosado diagonal se aprecia claramente, compuesto de una piedra diferente de la del enlosado para el enterramiento de los jesuitas. En medio del mismo, se dispone el enterramiento de la fundadora bajo la cúpula, lo que determina la importancia del lugar, donde anteriormente se encontraba el altar de las reliquias. La única salvedad reside en la reja, pues la actual está retrasada con respecto a la propuesta de Rebollar.

Atendiendo al Libro de Cuentas de la Capilla del Relicario de la obra ${ }^{67}$, la traza de Rebollar estaría dibujada en 1660 , el año en que se registran varios pagos a los canteros que trabajaron en el enlosado de la capilla. En 1663, el padre visitador Cachupin habla ya de las obras acometidas en el techo de la capilla ${ }^{68}$. En 1665 se vendieron varios relicarios de Ulloa ${ }^{69}$, algunos localizados

66 Plano dibujado por Gómez del Rebollar, s/fecha, AHN, MPD, consejos, 1743

67 Gastos del año 1660, 1660, AHN, Clero, jesuitas, libro 492: Libro de Cuentas de la Capilla del Relicario, fundada por D. ${ }^{a}$ Inés de Salazar y Mendoza, en el Colegio de la Compañia de Jesús de Villagarcía, ff. 70v.-72r.

68 Visita del Provincial Francisco Cachupin, 12 de enero de 1663, ACSLVC, archivador VI, carpeta C: Libro General de Ordenaciones y Memoriales de los Padres Provinciales en sus visitas a Villagarcía, desde su comienzo hasta su expulsión (1574-1767), f. 53v.

69 "Recibo por los desechos del Sagrario vendidos", 1665, AHN, Clero, jesuitas, libro 492: Libro de Cuentas de la Capilla del Relicario, fundada por D. ${ }^{a}$ Inés de Salazar y Mendoza, en el Colegio de la Compañía de Jesús de Villagarcía. Años 1637-1756, ff. 49r.-v. 


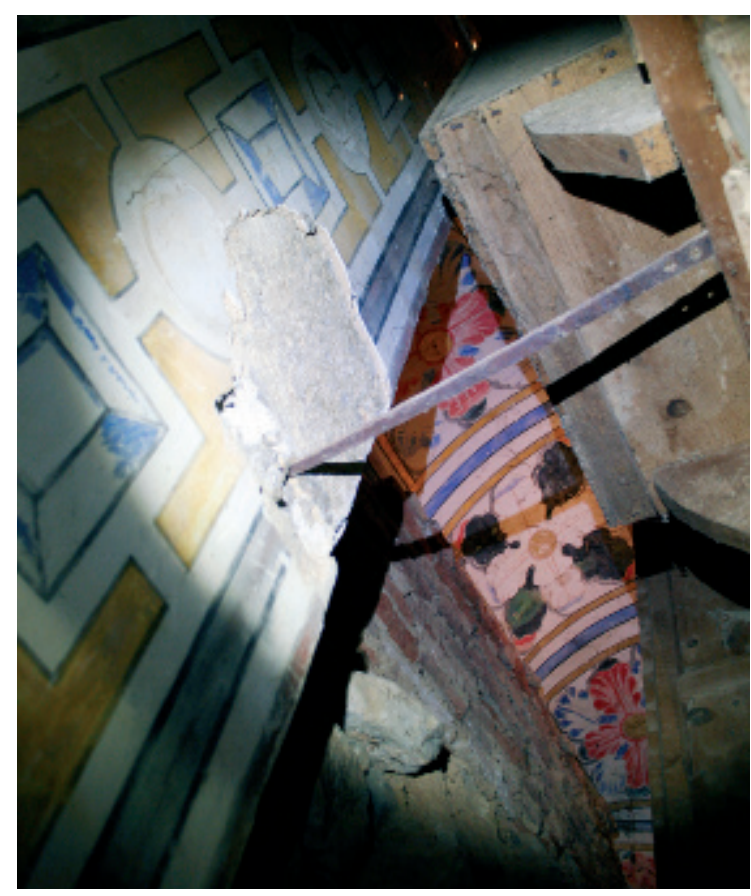

Fig. 5. Resto de pintura en la entrada de la sacristía para la capilla relicario barroca, h. 1665 . Actualmente detrás del retablo de San José.

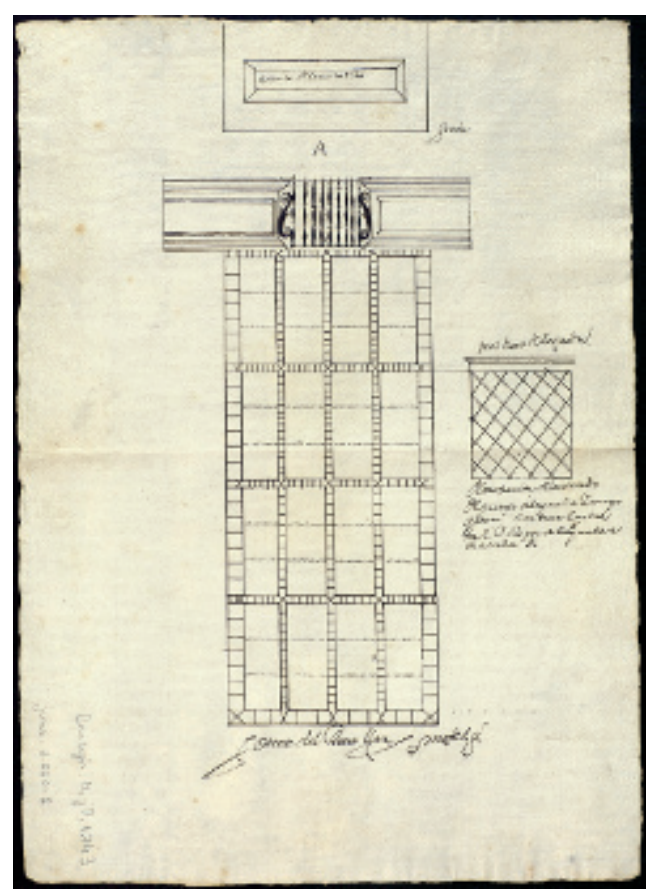

Fig. 6. Plano del suelo de la capilla relicario dibujado por Gómez del Rebollar, anterior a 1665. AHN, Mapas, planos y dibujos, Consejos, 1743.

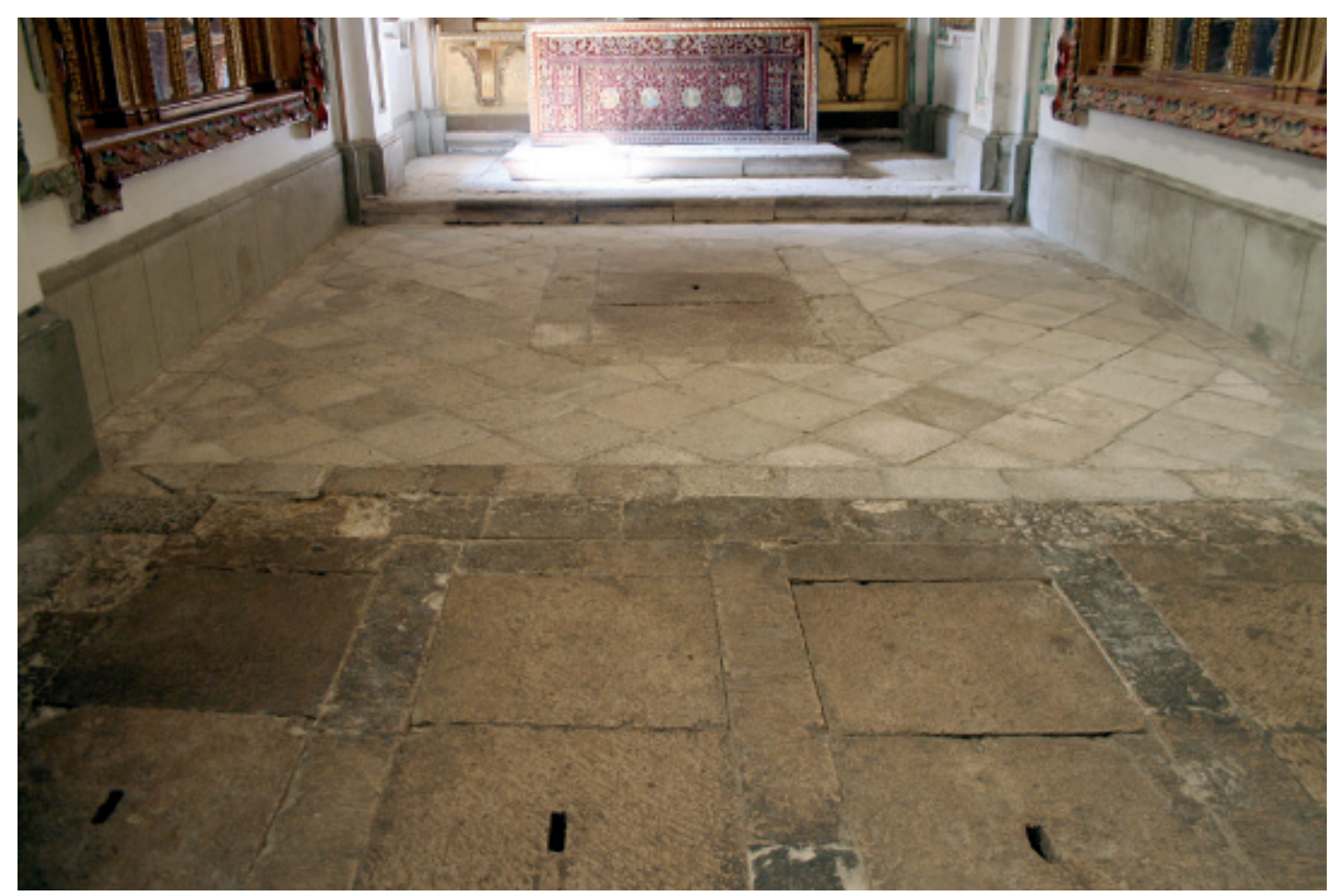

Fig. 7. Enlosado de la capilla relicario en la actualidad. 


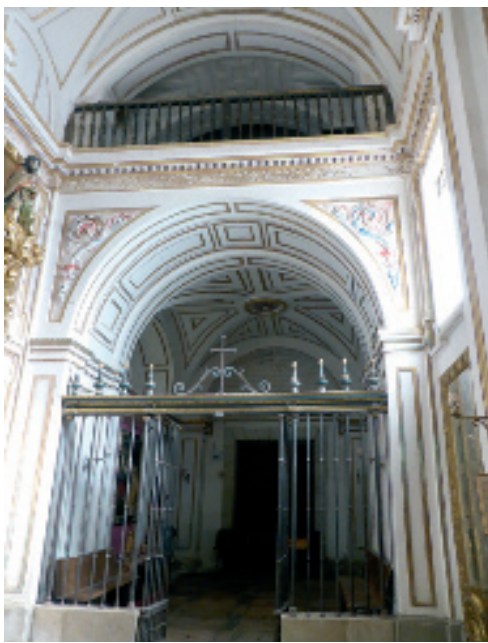

Fig. 8. Capilla relicario y el corillo en la actualidad.

en el antiguo graderío y recogidos en la antedicha "Memoria de las Reliquias, Imágenes y cosas devotas". En ese mismo año, se ajustó con Cristóbal Ruiz de Andino, escultor, la hechura del retablo ${ }^{70}$. Un año después, se procedió al desmantelamiento del antiguo graderío de las reliquias ${ }^{71}$ y a "quitar el tabernáculo".

Conforme avanzaba la obra, también se amplió el número de vanos para una mayor iluminación del espacio (figs. 8 y 9$)^{72}$. De hecho, en el muro exterior de la estructura actual se observa que algunos de los vanos antiguos fueron cegados para que los nuevos dirigiesen la luz a la cabecera de la capilla y al nuevo retablo. En algunas de las nuevas ventanas fueron colocadas las vidrieras ${ }^{73}$.

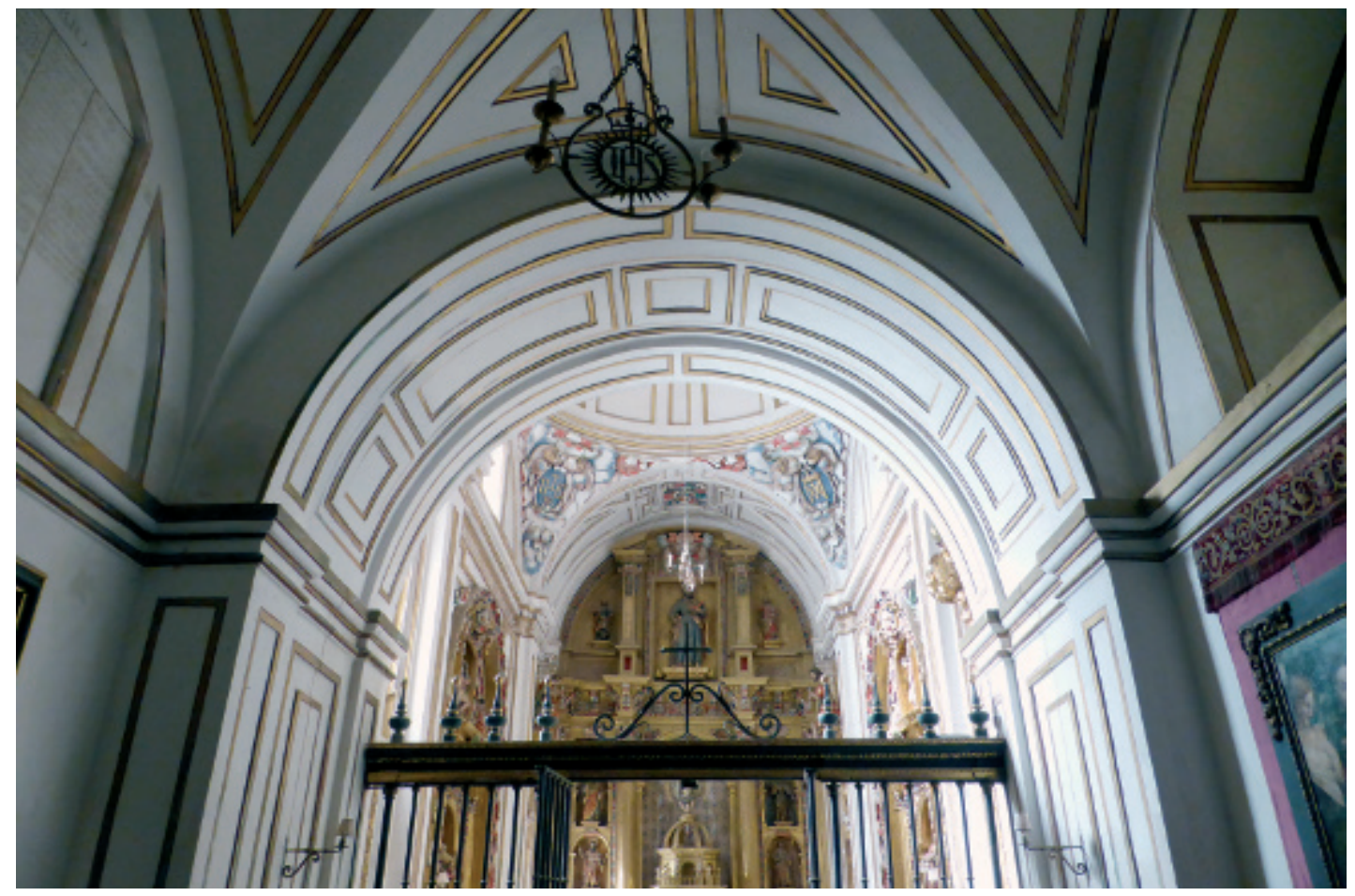

Fig. 9. Capilla relicario en la actualidad.

70 Martín González, 1951-52: 43-52.

71 "Varios peones que metieron piedra en el sagrario y ayudaron a quitar el tabernáculo", Obras del relicario, 1666, AHN, Clero, jesuitas, libro 492: Libro de Cuentas de la Capilla del Relicario, fundada por D. ${ }^{a}$ Inés de Salazar y Mendoza, en el Colegio de la Compañia de Jesús de Villagarcía. Años 1637-1756, f. 80r.

72 "Fábrica de la ventana que cae a la calle". Obras del relicario, 1666, AHN, Clero, jesuitas, libro 492: Libro de Cuentas de la Capilla del Relicario, fundada por D. ${ }^{a}$ Inés de Salazar y Mendoza, en el Colegio de la Compañía de Jesús de Villagarcía. Años 1637-1756, f. 81v.

73 "Más del corte de la bidriera alta del Sagrario que cae al claustro que tubo 50 palmos". Obras del relicario, 1666, AHN, Clero, jesuitas, libro 492: Libro de Cuentas de la Capilla del Relicario, fundada por D. ${ }^{a}$ Inés de Salazar y Mendoza, en el Colegio de la Compañia de Jesús de Villagarcía. Años 1637-1756, f. 85r. 
En 1672, Pedro Gómez del Rebollar labró el pedestal en el que se asentó la reja intermedia. Cristóbal Ruiz de Andino fue el encargado de realizar la puerta y reja de paso del claustro al Sagrario $^{74}$. Años más tarde, en 1679 , se acometió la obra de la nueva portada de la capilla, tanto de las puertas alacenas de madera como de la portada pétrea, adintelada y con frontón curvo partido en el que campa el escudo de Salazar. Asimismo se efectuaron los trabajos pertinentes para dar acomodo a la nueva sacristía del relicario ${ }^{75}$.

\section{Conclusiones}

En el presente estudio, hemos comprobado la disposición centralizada de un altar de reliquias cuando Magdalena de Ulloa levantó la capilla relicario, elemento visible tanto del lado del colegio como del de la iglesia. El altar contenía numerosísimas reliquias expuestas en siete gradas, un modelo que los jesuitas y otras órdenes acostumbraban usar en la segunda mitad del siglo XVI. Las reliquias, ubicadas en una capilla más bien oscura, se visualizaban solo en días especiales descorriendo los velos, creando una atmósfera mística. La ejecución de la capilla pudo ser dirigida por Juan de Nates, quien estuvo trabajando por lo menos hasta 1579 en Villagarcía de Campos, ya que la capilla se terminaba de edificar en 1577 aunque su amueblamiento no se completaría hasta 1585 .

La disposición espacial y sobre todo direccional de la capilla fue muy alterada a raíz de la decisión tomada por los jesuitas de que la capilla de Inés de Salazar se situara en la capilla de Ulloa. La donante había retirado la primera idea de construir una nueva capilla detrás de la iglesia, ciertamente pretenciosa, dotada en la cabecera de un espacio específico para el relicario-sagrario con gradas, como demuestra el dibujo aquí analizado. La cesión de Salazar de una parte de su futura capilla para enterrar a los padres jesuitas se materializó alargando la capilla de Ulloa hacia la iglesia. La nueva capilla dispone de una sola direccionalidad hacia el nuevo altar de estilo barroco, operación que conllevó la nueva ubicación del coro, el actual corillo junto al coro de la iglesia, y la conversión de la primera capilla colateral en la sacristía decorada al tono de la renovada capilla de Salazar.

\section{BIBLIOGRAFÍA}

Burrieza Sánchez, Javier (2003): "La recompensa de la eternidad. Los fundadores de los colegios de la Compañía de Jesús en el ámbito vallisoletano”. En: Iglesia y Religiosidad, Anales de la Universidad de Alicante, 21, Alicante, pp. 7-61.

Bustamante García, Agustín (1982): La arquitectura clasicista del foco vallisoletano (1561-1640). Valladolid: Institución Cultural Simancas.

Campos, Manoel de (1588): Relaçam do solenme reccebimento que se fez en Lisboa às santas reliquias a[ue] se levarám à igreja de S. Roque da Conpanhia de Iesu aos 28 de Ianero de 1588. Lisboa: Antonio Ribeiro.

Carrillo, Juan (1616): Relación histórica de la Real Fundación del monasterio de las Descalzas de S. Clara de la villa de Madrid. Madrid: Luis Sánchez.

Chevalier, Jean / Gheerbrant, Alain (2007): Diccionario de los símbolos. Barcelona: Herder.

Fernández Martín, Luis (1952): La Casa y el Colegio de Humanidades de Villagarcía de Campos. Bilbao [s.n.].

Fernández Martín, Luis (1998): “Tres testamentos y un relicario”. En: Rodríguez Herreras, Félix (ed.): Doña Magdalena de Ulloa (1598-1998): una mujer de Villagarcía de Campos (Valladolid), su profundo influjo social. Valladolid: Diputación Provincial de Valladolid, pp. 179-192.

García Chico, Esteban (1940): Documentos para el estudio del arte de Castilla. Arquitectos, I. Valladolid: Universidad de Valladolid.

74 Obras del relicario, 1672, AHN, Clero, jesuitas, libro 492: Libro de Cuentas de la Capilla del Relicario, fundada por D. ${ }^{a}$ Inés de Salazar y Mendoza, en el Colegio de la Compañia de Jesús de Villagarcía. Años 1637-1756, ff. 92v. y $93 \mathrm{r}$.

75 Obras del relicario, 1679, AHN, Clero, jesuitas, libro 492: Libro de Cuentas de la Capilla del Relicario, fundada por D. ${ }^{a}$ Inés de Salazar y Mendoza, en el Colegio de la Compañia de Jesús de Villagarcía. Años 1637-1756, f. 99r. 
García Chico, Esteban (1953-1954): "Los artistas de la Colegiata de Villagarcía de Campos”. En: Boletín del Seminario de Estudios de Arte y Arqueología, XX, Valladolid, pp. 43-80.

García Chico, Esteban (1957): La Colegiata de Medina del Campo y otros estudios. El Arte de Castilla. Valladolid: Gráficas Andrés Martín.

García Chico, Esteban (1979): Catálogo monumental de la provincia de Valladolid: Medina de Ríoseco. Valladolid: Institución Cultural de Simancas.

Idiáquez, Francisco Javier (1818): Prácticas espirituales para el uso de los Hermanos Novicios de la Compañia de Jesús del Noviciado de Villagarcía. Madrid: Imprenta de Tejado.

Martín González, Juan José (1951-52): “El Relicario de la Colegiata de Villagarcía de Campos (Valladolid)”. En: Boletín del Seminario de Estudios de Arte y Arqueología, XVIII, Valladolid, pp. 43-52.

Martín González, Juan José (1957): Arquitectura barroca vallisoletana. Valladolid: Universidad de Valladolid.

Martín González, Juan José (1957b): "La Colegiata de Villagarcía de Campos y la arquitectura herreriana". En: Boletín del Seminario de Estudios de Arte y Arqueología, XXIII, Valladolid, pp. 19-40.

Morales, Ambrosio de (1568): La vida, el martyrio, la invención, las grandezas y translaciones de los gloriosos niños mártires Santos Justo y Pastor. Y el solemne triunfo con que fueron recibidas sus santas reliquias en Alcalá de Henares en su postrera traslación. Alcalá de Henares: Andrés de Angulo.

Morales, Ambrosio de (1765): Viage de Ambrosio de Morales por Orden del rey D. Phelipe II a los reynos de León, y Galicia, y Principado de Asturias, para conocer las reliquias de Santos, Sepulcros Reales y libros manuscritos de las Cathedrales y Monasterios. Madrid: Antonio Marín.

Morán, Miguel / Checa Cremades, Fernando (1985): El coleccionismo en España. De la cámara de maravillas a la galería de pinturas. Madrid: Cátedra.

O’Neill, Charles / Domínguez, Joaquín María (2001): Diccionario Histórico de la Compañía de Jesús. Biográfico-Temático, tomo I. Madrid: Institutum Historicum, Universidad Pontificia de Comillas.

Orti, Marco Antonio (1640): Siglo Quarto de la Conquista de Valencia. Valencia: Impresor Juan Bautista Marçal.

Pérez de Castro, Ramón (2000): “Actividad artística y talleres de ensamblaje en Medina de Ríoseco (1650-1675), Lucas González”. En: Boletín del Seminario de Estudios de Arte y Arqueología, LXVI, Valladolid, pp. 269-290.

Pérez Picón, Conrado (1982): Villagarcía de Campo. Estudios histórico-artístico. Valladolid: Institución Cultural Simancas, Diputación de Valladolid.

Pirri, Pedro, y otros (1952): Villagarcía de Campos. Evocación histórica de un pasado glorioso. Bilbao: El Mensajero del Corazón de Jesús.

Pirri, Pedro (1952): "Origen y desarrollo arquitectónico de la iglesia y colegio de Villagarcía de Campos". En: Pirri, Pedro/otros: Villagarcía de Campos. Evocación histórica de un pasado glorioso. Bilbao: El Mensajero del Corazón de Jesús, pp. 13-24.

Pirri, Pietro (1970): Giuseppe Valeriano S.I. Architetto Pittore, 1542-1596. Roma: Institutum historicum S.I.

Puente, Luis de la (1615): Vida del P. Baltasar Alvarez. Madrid: Luis Sánchez.

Rodríguez G. de Ceballos, Alfonso (1966): "Juan de Herrera y los jesuitas: Valeriano, Villalpando, Ruiz, Tolosa". En: Archivum Historicum Societatis Iesu, XXXV, Roma, pp. 19-30.

Rodríguez G. de Ceballos, Alfonso (1969): Estudios del Barroco salmantino. El colegio Real de la Compañía de Jesús (1617-1779). Salamanca: Centro de Estudios Salmantinos.

Rodríguez Herreras, Félix (coord.) (1998): Doña Magdalena de Ulloa (1598-1998). Una mujer de Villagarcía de Campos (Valladolid). Su profundo influjo social. Valladolid: Diputación Provincial de Valladolid.

Sandoval, Prudencio de (1604): Historia de la vida y hechos del Emperador Carlos: trátense en esta primera parte los hechos desde el año 1500, hasta el año 1528, vol. I. Valladolid: Sebastián de Cañas.

Urrea Fernández, Jesús (coord.) (2009): Del Olvido a la Memoria, VII, Patrimonio Provincial Restaurado (2066-2008). Valladolid: Junta Castilla y León, Diputación de Valladolid, Arzobispado de Valladolid.

Villañafe, Juan de (1723): La limosnera de Dios. Relación Histórica de la Vida, y Virtudes de Doña Magdalena de Ulloa, Toledo, Ossorio y Quiñones, muger del excelentissimo señor Luis Méndez de Quixada. Salamanca: Imprenta de Francisco García Onorato.

Fecha de recepción: 27-IX-2016

Fecha de aceptación: 17-I-2017 